within the capsule, he did not mean to assert that bony union could be effected in every case of fracture in this situation. He well knew, that in some cases the fractured surfaces may not be brought sufficiently into contact, in consequence of the situation and great mobility of the head of the thigh bone when separated from the neck; but he was disposed to think, that in the majority of cases this might be accomplished; and in those cases where bony union cannot be produced sufficiently extensive to support the weight of the body, we should gain much for the patient, by producing a very short ligamentous union, which, by holding the fractured surfaces together, would prevent the shaft of the bone, or trochanter, from being pushed up upon the dorsum of the ilium, when the weight of the body is thrown upon the limb, and thus prevent that horrible clandication and inability to walk without the use of crutches, which we see in the worst of these cases. Mr. Amesbury wished it to be understood, that in his opinion it would hereafter be found, that those fractures which, under common treatment, unite by the intervention of short ligaments, may be made to unite by bone, and that those which, under common treatment, unite only by ligaments of sufficient length to allow of an exteut of inotion equal to two inches, or more, between the fractured surfaces, may, by better management, be made to unite by very short ligaments, and in this way, whether the fracture unite by bone or not, the patient would be much banefited. He would expect to produce union by bone where union is usually effected by short ligament, and union, at all events, by short ligament, in those cases where no union is usually produced, calculated to be of any service to the patient. He had heard a great deal about the propriety of endeavouring to produce short ligamentous union in fractures of the patella and olecranon; but he was not acquainted with any surgeon or author, who says one word ahout the propriety of doing this in fractures of the neck of the thigh bone within the capsule. Mr. Amesbury had said, that the treatment usually followed in these cases was, in his opinion, very bad, and had promised the Society that he would show them the contrivance which he had introduced for the management of fractures of the neck of the femur. This contrivance the Society shorld have an opportunity of inspecting at the next meeting.

The time devoted to discussion having expired, the President (Dr. Haslam) begged to know, if it were the wish of the Society that the subject: now before them should be resumed at the next meeting? Upon this being put to the Society, it was decided in the affirmative by a show of hands.

\section{ROYAL INFIRMARY.}

"Venesection in the cold stuge of Intermittents.

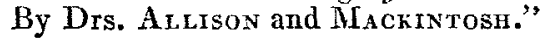

THE simultaneous occurrence of the publication of a paper on bleeding in the cold stage of intermittent fever, by Dr. Mackintosh, in the last Number of the "Blue Journal," and the admission of a patient affected with this disease into the hospital, induced Dr. Allison to try the efficacy of this novel practice in the present case. Dr. Mackintosh, as appears from his essay, no wise daunted by the denunciations of many writers against the use of the lancet in the cold stage of intermittents, first heroically put the treatment to the test of experiment on his own person, while labouring under that complaint. Since that time he has had many opportunities of witnessing the beneficial effects of blood-letting in this stage of the disease. But eight cases, however, are recorded, and the majority even of these picked samples is any thing but satisfactory as to the general utility of his proposal. In all these eight cases of various degrees of intensity and duration, venesection was performed during the cold stage, and, in all, (no other remedies, except laxatives, having been previously employed,) the rigors were almost immediately stopped, and the hot stage either entirely prevented, or considerably mitigated. The two first cases are represented as completely successful; no other remedy, except mild-ajerients, than the lancet, having been employed, and no rigors having returned after its use. Here, however, the success of the plan terminates, or at least becomes doubtful. In the third case, the patient had an interval of eight days after the first bleeding, without rigors; but they then refurned, when he was bled a second time, with nearly similar results. He had, subsequently to this period, several rigors, which, gradually declining, he was dismissed as cured; but in a month afterwards the complaint recurred, when, without one drop of blood being abstracted on the occasion, quinine effected a complete cure. In the fourth case, renesection also put the rigor to flight, and diminished the succeeding paroxysms; but they came on again with original violence, when the patient being put on the use of quinine, and after one hundred and sixteen grains of that jreparation had been swallowed, his cure is proclaimed as the consequence of blood-letting! The nfth case aiso affords a further illustration of the virtues of the quinine. The patient was bled, the paroxysms ab. 
breviated; they returned to the eighth or tenth time. 'The Loyalian specific was now administered, and " he took up his bed and walked." The sixth case presented similar proofs of the efficacy of this drug. In the seventh, however, it was not employed; but as the case did not come under the immediate cognizance of Dr. Mackintosh, it may be passed over as an appendix to eke out the defence of blood-letting. In the eighth and last case, the rigors having repeatedly occurred after the lancet, the quinine was resorted to, and with the happiest effects; so that in five out of these eight cases, the paroxysms recurred, and the disease may be said to have been cured by quinine instead of phlebotomy. Dr. Mackintosh does not andertake to explain on what principle the abstraction of blood cures an intermittent. This, indeed, is rather surprising; for presumptuous conclusions are usually coupled with a corresponding temerity of speculation. It may, however, be inferred from the pathology of this disease, that his supposed remedy is as erroneous in theory, as it is abortive in its application. It has been long assumed as a certainty, that the pain of head, back, hypochondriac region, the difficulty of breathing, oppression of the precordia, and occasional irregularity of the pulse, which characterise a paroxysm of this complaint, are severally produced by a congestion of blood in the brain, the lungs, the heart, the liver, the spleen, \&c., in short, by a translation of the blood from the external to the internal parts of the system. This congestion of blood in the interior organs of the body, it should be recollected, is but an effect, a symptom, and obviously depending on some cause influencing the motive powers of the vascular system.

Now it is an acknowledged axiom in pathology, that our chief attention and remedial agents should be directed to the cause and not to any single symptom of a disease. Dr. Makintosh's practice manifestly violates this pathological canon; for it cannot be readily imagined in what other manner venesection suspends the paroxysm than by removing a portion of the blood from those vessels in which it is temporarily accumnlated, and thus restoring, mechanically, the balance between the venous and arterial symptoms. Indeed, we have pretty direct evidence, that this venous turgescence of internal oryans does not constitute the disease, and that remedies solely directed to relieve this state of the vascular system leave the cause of the complaint untouched; for we know that the consequences attributed to venesection in these cases are notoriously produced by agents which act only on the nerrous system, such as opium, ardent spirits, spices, quinine, nay, even by mental emotions. 'Tis true, blood-letting may

No. 188. extend its influence farther than the mere disgorgement of the distended vessels, but the frequent recurrence of the rigors, after the abstraction of blood, would at least seem to indicate that the relief procured is of a mechanical nature, and that there still latently exists some cause for the reproduction of the phenomena. We should, bowever, be perfectly satisfied with the absurd proposition of curing a disease by relieving one of its symptoms, and be quite content with our ignorance of the modus operandi of a specific, if it only realised our expectations of any agent bearing the charming name; but the following case, and those already detailed, deprives us of all such. hope, and Dr. Mackintosh an apology, for his sanguinary practice.

The subject of this case, J. Bennet, had an intermittent fourteen years ago, in Spain, and has been affected with it more or less for the last nine months, six of which he spent in the West Indies. Previous to his admission he has had several paroxysms, accompanied with and followed by the usual symptoms which occur in the cold, hot, and intermittent stages of the complaint. Sixteen ounces of blood were taken from his arm during the cold stage on the 27 th ult., when all his pains and shivering ceased for the time. Having taken opiate draughts, however, and the arsenical solution, before the abstraction of the blood, the share which the lancet had in stopping the fit is less easily appreciated. The employment of any medicine in the case is on this account to be regretted, as it is by the unassisted trial of any new proposition that its specific value can be precisely ascertained. In a disease where delay was not dangerous, Dr. Allison, who would call a coach in a syllogism, would have acted much more in conformity with his logical acumem, if in this instance he had withheld all drugs and left the venesection to work its own way. Not that the evidence of the inadequacy of this practice could have been more clearly demonstrated; for the patient, since the bleeding, has had a rigor much more severe than any since his late attack, but that a more impartial trial would have been given to the proposal. From this and the other cases recited, it is not probable that the practice will be ever generally adopted, as its use seems to be indicated in persons of a robust habit, or in cases where death is threatened during the paroxysm by asphyxia or convulsions ; for it cannot be supposed that practitioners will take out their lancet every time a cold stage comes on, a practice which no constitution would be able to support.

Scotes.

Edinburgh, March 31, 1827. 